NBER WORKING PAPER SERIES

\title{
INTERMEDIATE GOODS, WEAK LINKS, AND SUPERSTARS: A THEORY OF ECONOMIC DEVELOPMENT
}

\author{
Charles I. Jones \\ Working Paper 13834 \\ http://www.nber.org/papers/w13834 \\ NATIONAL BUREAU OF ECONOMIC RESEARCH \\ 1050 Massachusetts Avenue \\ Cambridge, MA 02138 \\ March 2008
}

I would like to thank Daron Acemoglu, Andy Atkeson, Pol Antras, Susanto Basu, Paul Beaudry, Roland Benabou, Olivier Blanchard, Bill Easterly, Xavier Gabaix, Luis Garicano, Pierre-Olivier Gourinchas, Chang Hsieh, Pete Klenow, Guido Lorenzoni, Kiminori Matsuyama, Ed Prescott, Dani Rodrik, Richard Rogerson, David Romer, Michele Tertilt, Alwyn Young and seminar participants at Berkeley, Brown, Chicago, the Chicago GSB, the LSE, the NBER growth meeting, Northwestern, Penn, Princeton, the San Francisco Fed, Stanford, Toulouse, UCLA, USC, and the World Bank for helpful comments. I am grateful to Urmila Chatterjee, On Jeasakul, and Mu-Jeung Yang for excellent research assistance, to the Hong Kong Institute for Monetary Research and the Federal Reserve Bank of San Francisco for hosting me during the early stages of this research, and to the National Science Foundation and the Toulouse Network for Information Technology for financial support. The views expressed herein are those of the author(s) and do not necessarily reflect the views of the National Bureau of Economic Research.

NBER working papers are circulated for discussion and comment purposes. They have not been peerreviewed or been subject to the review by the NBER Board of Directors that accompanies official NBER publications.

(C) 2008 by Charles I. Jones. All rights reserved. Short sections of text, not to exceed two paragraphs, may be quoted without explicit permission provided that full credit, including $\bigcirc$ notice, is given to the source. 
Intermediate Goods, Weak Links, and Superstars: A Theory of Economic Development

Charles I. Jones

NBER Working Paper No. 13834

March 2008

JEL No. O11,O4

\begin{abstract}
$\underline{\text { ABSTRACT }}$
Per capita income in the richest countries of the world exceeds that in the poorest countries by more than a factor of 50. What explains these enormous differences? This paper returns to several old ideas in development economics and proposes that linkages, complementarity, and superstar effects are at the heart of the explanation. First, linkages between firms through intermediate goods deliver a multiplier similar to the one associated with capital accumulation in a neoclassical growth model. Because the intermediate goods' share of revenue is about $1 / 2$, this multiplier is substantial. Second, just as a chain is only as strong as its weakest link, problems at any point in a production chain can reduce output substantially if inputs enter production in a complementary fashion. Finally, the high elasticity of substitution associated with final consumption delivers a superstar effect: GDP depends disproportionately on the highest levels of productivity in the economy. This paper builds a model with links across sectors, complementary inputs, and highly substitutable consumption, and shows that it can easily generate 50-fold aggregate income differences.
\end{abstract}

Charles I. Jones

University of California, Berkeley

Department of Economics

549 Evans Hall, \#3880

Berkeley, CA 94720-3880

and NBER

chad@econ.berkeley.edu 
CHARLES I. JONES

\section{INTRODUCTION}

By the end of the 20th century, per capita income in the United States was more than 50 times higher than per capita income in Ethiopia and Tanzania. Dispersion across the 95th-5th percentiles of countries was more than a factor of 32. What explains these profound differences in incomes across countries? ${ }^{1}$

This paper returns to several old ideas in the development economics literature and proposes that linkages, complementarity, and superstar effects are at the heart of the explanation. Intermediate goods provide links between sectors that create a productivity multiplier. Low productivity in electric power generation reduces output in banking and construction. But this reduces the ease with which the electricity industry can build new dams and therefore further reduces output in electric power generation. This multiplier effect is similar to the multiplier associated with capital accumulation in a neoclassical growth model. In fact, intermediate goods are just another form of capital, albeit one that depreciates fully in production. Because the intermediate goods' share of revenue is approximately $1 / 2$, the intermediate goods multiplier is large.

Because of complementarity, high productivity in a firm requires a high level of performance along a large number of dimensions. Textile producers require raw materials, knitting machines, a healthy and trained labor force, knowledge of how to produce, security, business licenses, transportation networks, electricity, etc. These inputs enter in a complementary fashion, in the sense that problems with any input can substantially reduce overall output. Without electricity or production knowledge or raw materials or security or business licenses, production is likely to be severely hindered.

Finally, a high elasticity of substitution associated with final consumption delivers a superstar effect, reminiscent of Rosen (1981). In the absence of

\footnotetext{
${ }^{1}$ Recent work on this topic includes Romer (1994), Klenow and Rodriguez-Clare (1997), Prescott (1998), Hall and Jones (1999), Parente and Prescott (1999), Howitt (2000), Parente, Rogerson and Wright (2000), Acemoglu, Johnson and Robinson (2001), Klenow and RodriguezClare (2005), Manuelli and Seshadri (2005), Caselli and Coleman (2006), Armenter and Lahiri (2006), Erosa, Koreshkova and Restuccia (2006), Marimon and Quadrini (2006), and Restuccia, Yang and Zhu (2006).
} 
distortions, GDP depends disproportionately on the highest levels of productivity in the economy.

The contribution of this paper is to build a model in which these ideas can be made precise. We show that complementarity, superstar effects, and linkages amplify small distortions to the allocation of resources. With plausible differences in distortions and productivity across countries, we can easily explain 50 -fold differences in per capita income.

The approach taken in this paper can be compared with the recent literature on political economy and institutions; for example, see Acemoglu and Johnson (2005) and Acemoglu and Robinson (2005). This paper is more about me-

chanics: can we develop a plausible mechanism for getting a big multiplier, so that relatively modest distortions lead to large income differences? The modern institutions approach builds up from political economy. This is useful in explaining why the allocations in poor countries are inferior - for example, why investment rates in physical and human capital are so low - but the institutions approach ultimately still requires a large multiplier to explain income differences. As just one example, even if a political economy model explains observed differences in investment rates across countries, the model cannot explain 50-fold income differences if it is embedded in a neoclassical framework. The political economy approach explains why resources are misallocated; the approach here explains why misallocations lead to large income differences. Clearly, both steps are needed to understand development.

\section{LINKAGES, COMPLEMENTARITY, AND SUPERSTARS}

We begin by discussing briefly the key mechanisms at work in this paper. These mechanisms are conceptually distinct — one can have linkages without complementarity, for example — but they interact in important ways. 


\subsection{Linkages through Intermediate Goods}

The notion that linkages across sectors can be central to economic performance dates back at least to Leontief (1936), which launched the field of input-output economics. Hirschman (1958) emphasized the importance of complementarity and linkages to economic development. A large subsequent empirical literature constructed input-output tables for many different countries and computed sectoral multipliers.

In what may prove to be an ill-advised omission, these insights have not generally be incorporated into modern growth theory. Linkages between sectors through intermediate goods deliver a multiplier very much like the multiplier associated with capital in the neoclassical growth model. More capital leads to more output, which in turn leads to more capital. This virtuous circle shows up mathematically as a geometric series which sums to a multiplier of $\frac{1}{1-\alpha}$, if $\alpha$ is capital's share of overall revenue. Because the capital share is only about $1 / 3$, this multiplier is relatively small: differences in investment rates are too small to explain large income differences, and large total factor productivity residuals are required. This led a number of authors to broaden the definition of capital, say to include human capital or organizational capital. It is generally recognized that if one can get the capital share up to something like $2 / 3$ - so the multiplier is 3 - large income differences are much easier to explain without appealing to a large residual. ${ }^{2}$

Intermediate goods generate this same kind of multiplier. Inferior highways that result from corruption can reduce output in a range of sectors, including construction. But this in turn further reduces the output of highways. In the model below, this multiplier depends on $\frac{1}{1-\sigma}$, where $\sigma$ is the share of intermediate

\footnotetext{
${ }^{2}$ Mankiw, Romer and Weil (1992) is an early example of this approach to human capital. Chari, Kehoe and McGrattan (1997) introduced "organizational capital" for the same reason. Howitt (2000) and Klenow and Rodriguez-Clare (2005) use the accumulation of ideas to boost the multiplier. More recently, Manuelli and Seshadri (2005) and Erosa et al. (2006) have resurrected the human capital story in a more sophisticated fashion. The controversy in each of these stories is over whether or not the additional accumulation raises the multiplier sufficiently. Typically, the problem is that the magnitude of a key parameter is difficult to pin down.
} 
inputs in gross output. This share is approximately $1 / 2$ in the United States and in other countries, delivering a multiplier of 2 . In the model, the overall multiplier (for example, on productivity) is the product of the intermediate goods and capital multipliers: $\frac{1}{1-\sigma} \times \frac{1}{1-\alpha}=2 \times 3 / 2=3$. Combining a neoclassical story of capital accumulation with a standard treatment of intermediate goods therefore delivers a very powerful engine for explaining income differences across countries. Related insights pervade the older development literature but have not had a large influence on modern growth theory. The main exception is Ciccone (2002), which appears to be underappreciated. ${ }^{3}$

\subsection{The Role of Complementarity}

A large multiplier in growth models is a two-edged sword. On the one hand, it is extremely useful in getting realistic differences in investment rates, productivity, and distortions to explain large income differences. However, the large multiplier has a cost. In particular, theories of economic development often suffer from a "magic bullet" critique. If the multiplier is so large, then solving the development problem may be quite easy. For example, this is a potential problem in the Manuelli and Seshadri (2005) paper: small subsidies to the production of output or small improvements in a single (exogenous) productivity level have enormous long-run effects on per capita income in their model. If there were a single magic bullet for solving the world's development problems, one would expect that policy experimentation across countries would hit on it, at least eventually. The magic bullet would become well-known and the world's development problems would be solved.

\footnotetext{
${ }^{3}$ Ciccone develops the multiplier formula for intermediate goods and provides some quantitative examples illustrating that the multiplier can be large. The point may be overlooked by readers of his paper because the model also features increasing returns, externalities, and multiple equilibria. Yi (2003) argues that tariffs can multiply up in much the same way when goods get traded multiple times during the stages of production. Interestingly, the intermediate goods multiplier shows up most clearly in the economic fluctuations literature; see Long and Plosser (1983), Basu (1995), Horvath (1998), Dupor (1999), Conley and Dupor (2003), and Gabaix (2005). See also Hulten (1978).
} 
This is where the second insight of this paper plays it role. Because of complementarity, the development problem may be hard to solve. In any production process, there are ten things that can go wrong that will sharply reduce the value of production. In rich countries, there are enough substitution possibilities that these things do not often go wrong. In poor countries, on the other hand, any one of several problems can doom a project. Obtaining the instruction manual for how to produce socks is not especially useful if the import of knitting equipment is restricted, if cotton and polyester threads are not available, if property rights are not secure, and if the market to which these socks will be sold is unknown. Complementarity is at the heart of the O-ring story put forward by Kremer (1993). The idea in this paper is similar, but the papers differ substantially in crucial ways. These differences will be discussed in detail below.

Linkages through intermediate goods provide a large multiplier, while complementarity means that there is typically not a single magic bullet that can exploit this multiplier. Occasionally, of course, there is. Fixing the last bottleneck to development can have large effects on incomes, which may help us to understand growth miracles.

\subsection{An Example of Complementarity}

Standard models of production often emphasize the substitutability of different inputs. While substitution will play an important role in the model that follows, so will complementarity. Since this is less familiar, we begin by focusing our attention on complementary inputs. ${ }^{4}$

For this purpose, it is helpful to begin with a simple example. Suppose you'd like to set up a factory in China to make socks. The overall success of this project requires success along a surprisingly large number of different dimensions. These different activities are complementary, so that inefficiencies on any one dimension can sharply reduce overall output.

\footnotetext{
${ }^{4}$ Milgrom and Roberts (1990) argue that there are extensive complementarities involved in production by modern firms, related to marketing, manufacturing, engineering, design, and organization.
} 
First, the firm needs the basic inputs of production. These include cotton, silk, and polyester; the sock-knitting machines that spin these threads into socks; a competent, healthy, and motivated workforce; a factory building; electricity and other utilities; a means of transporting raw materials and finished goods throughout the factory, and so on.

Apart from the physical production of socks, other activities are required to turn raw materials into revenue. The entire production process must be kept secure from theft or expropriation. The sock manufacturer must match with buyers, perhaps in foreign markets, and must find a way to deliver the socks to these buyers. Legal requirements must also be met, both domestically and in foreign markets. Firms must acquire the necessary licenses and regulatory approval for production and trade.

Finally, the managers in the firm require many different kinds of knowledge. They need to know the technical details of how to make socks. They need to know how to manage their workforce, how to run an accounting system, how to navigate a perhaps-intricate web of legal requirements, etc. Notice that even if the basic inputs are available through trade, these last two paragraphs of requirements are to a great extent nontradable. Trade may help alleviate the problems in this paper, but there are likely to be enough non-traded inputs that domestic weak links can be crucial.

The point of this somewhat tedious enumeration is that production - even of something as simple as a pair of socks - involves a large number of necessary activities. If any of these activities are performed inefficiently, overall output can be reduced considerably. Without a reliable supply of electricity, the sockmaking machines cannot be utilized efficiently. If workers are not adequately trained or are unhealthy because of contaminated water supplies, productivity will suffer. If export licenses are not in order, the socks may sit in a warehouse rather than being sold. If property is not secure, the socks may be stolen before they can reach the market. 


\subsection{Modeling Complementarity and Substitution}

A natural way to incorporate varying degrees of complementarity and subtitution is with a constant elasticity of substitution (CES) function. For example, suppose

$$
Y=\left(\int_{0}^{1} z_{i}^{\eta} d i\right)^{1 / \eta}
$$

Let $z_{i}$ denote a firm's purchases of the $i^{t h}$ input, and assume a continuum of intermediate inputs are necessary for production. In terms of our sock example, $z_{a}$ could be the quality of the instructions the firm has for making socks. $z_{b}$ could be number of sock-making machines, $z_{c}$ might represent the extent to which the relevant licenses have been obtained, and so on.

The elasticity of substitution among these activities is $1 /(1-\eta)$, but this (or its inverse) could easily be called an elasticity of complementarity instead. For intermediate inputs, it is plausible to assume $\eta<0$, so the elasticity of substitution is less than one. It is difficult to substitute electricity for transportation services or raw materials in production. Inputs are more complementary than in the usual Cobb-Douglas case $(\eta=0)$.

Complementarity puts extra weight on the activities in which the firm is least successful. This is easy to see in the limiting case where $\eta \rightarrow-\infty$; in this case, the CES function converges to the minimum function, so output is equal to the smallest of the $z_{i}$

This intuition can be pushed further by noting that the CES combination in equation (1) is called the power mean of the underlying $z_{i}$ in statistics. The power mean is just a generalized mean. For example, if $\eta=1, Y$ is the arithmetic mean of the $z_{i}$. If $\eta=0$, output is the geometric mean (Cobb-Douglas). If $\eta=-1$, output is the harmonic mean, and if $\eta \rightarrow-\infty$, output is the minimum of the $z_{i}$. From a standard result in statistics, these means decline as $\eta$ becomes more negative. Economically, a stronger degree of complementarity puts more weight 
FIGURE 1. How $\eta$ Controls the Power Mean

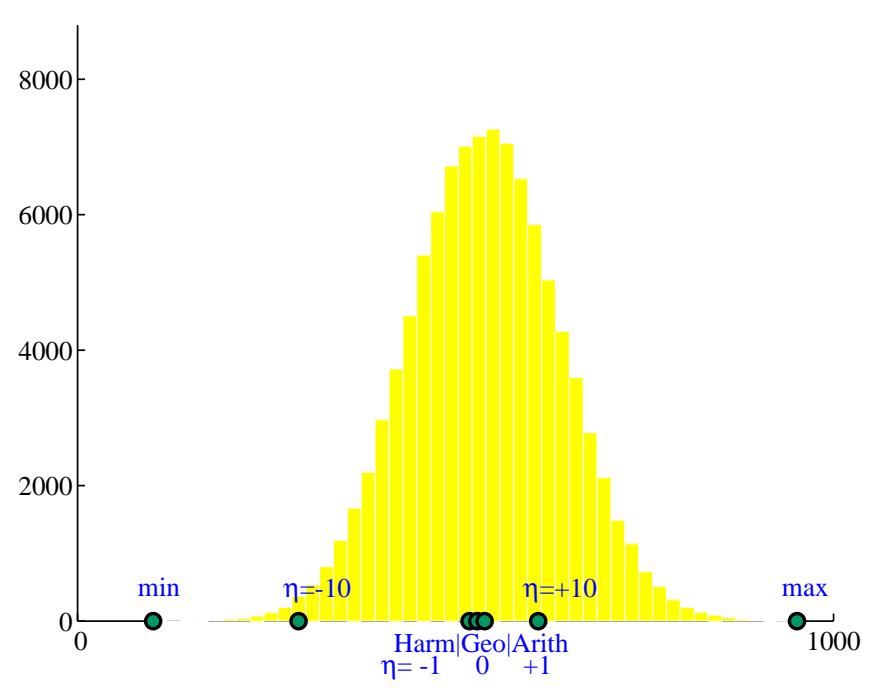

The graph shows a range of power means computed using different curvature parameters: the higher the curvature parameter, the higher the power mean. The historgram reflects 100,000 draws from a normal distribution.

on the weakest links and reduces output. ${ }^{5}$ These differences are illustrated in Figure 1.

Going in the other direction, if $\eta \rightarrow+\infty$, output converges to the maximum of the $z_{i}$, a "superstar" kind of production function, like that studied by Rosen (1981). More generally, the higher is $\eta$, the further up the distribution is the power mean. This case is not usually emphasized in growth models - notice that it implies a negative elasticity of substitution — but it turns out to play an important and intuitive role in our model.

\footnotetext{
${ }^{5}$ Benabou (1996) studies this approach to complementarity. Interestingly, standard intertemporal preferences with a constant relative risk aversion coefficient greater than one represent a familiar example.
} 


\subsection{Comparing to Kremer's O-Ring Approach}

It is useful to compare the way we model complementarity with the O-ring theory of income differences put forward by Kremer (1993). Superficially, the theories are similar, and the general story Kremer tells is helpful in understanding the current paper: the space shuttle Challenger and its seven-member crew are destroyed because of the failure of a single, inexpensive rubber seal.

This paper differs crucially in terms of how the general idea gets implemented. Kremer offers the basic insight that complementarity can generate a large multiplier by focusing on the extreme case in which all inputs combine in a Leontief fashion. The ratio of incomes between a rich and poor country, then, essentially depends on the extent to which the least productive task in the rich country is much more productive than the least productive task in the poor country: what matters is the ratio of minimums. It is not obvious in Kremer's paper how to extend his analysis to more standard production setups. That was an initial motivation of this paper, and in the process, we uncover very different results associated with the intermediate goods multiplier and superstar effects. ${ }^{6}$

\section{SETTING UP THE MODEL}

We now apply this basic discussion of complementarity, substitution, and linkages to construct a theory of economic development.

\subsection{The Economic Environment}

A continuum of goods indexed on the unit interval by $i$ are produced in this economy using a relatively standard Cobb-Douglas production function:

$$
Y_{i}=A_{i}\left(K_{i}^{\alpha} H_{i}^{1-\alpha}\right)^{1-\sigma} X_{i}^{\sigma},
$$

\footnotetext{
${ }^{6}$ Kremer does not emphasize that his approach embodies a Leonteif technology. Blanchard and Kremer (1997) formalize this interpretation and study a model of chains of production in order to understand the large declines in output in the former Soviet Union after 1989. Grossman and Maggi (2000), motivated in part by Kremer (1993), study trade between countries when production functions across sectors involve different degrees of complementarity. Other related papers include Murphy, Shleifer and Vishny (1989), Becker and Murphy (1992), Rodriguez-Clare (1996), and Rodrik (1996).
} 
where $\alpha$ and $\sigma$ are both between zero and one. $K_{i}$ and $H_{i}$ are the amounts of physical capital and human capital used to produce good $i$, and $A_{i}$ is an exogenously-given productivity level. The novel term in this production specification is $X_{i}$, which denotes the quantity of intermediate goods used to produce variety $i$.

Each of these fundamental goods in the economy can be used for one of two purposes: as a final good $\left(c_{i}\right)$ or as an intermediate input $\left(z_{i}\right)$. Therefore,

$$
c_{i}+z_{i}=Y_{i}
$$

The next two equations show how these uses affect the economy. In principle, we could specify a utility function over the continuum of final consumption uses. Instead, it proves more convenient (for modeling capital) to follow the standard trick of aggregating these final uses into a single final good, which will represent GDP in this economy:

$$
Y=\left(\int_{0}^{1} c_{i}^{\theta} d i\right)^{1 / \theta}, \quad 0<\theta<1 .
$$

These final consumption goods aggregate up with an elasticity of substition greater than one. Such an aggregator is standard in the literature, dating back to Dixit and Stiglitz (1977), and there are solid estimates of this elasticity that we will appeal to when it comes time for quantitative analysis.

Whereas consumption goods combine with an elasticity of substitution greater than one in producing GDP (or utility), intermediate inputs combine with an elasticity of substitution less than one. This is the key place where "weak links" enter the model:

$$
X=\left(\int_{0}^{1} z_{i}^{\rho} d i\right)^{1 / \rho}, \quad \rho<0 .
$$

This aggregate intermediate good is what gets used by the various sectors of the economy. To keep the model simple and tractable, we assume that the same combination of intermediate goods is used to produce each variety (though 
potentially in a different quantity). Hence, the resource constraint: ${ }^{7}$

$$
\int_{0}^{1} X_{i} d i \leq X .
$$

An example illustrating the consumption and intermediate goods may be helpful here. Varieties that are used as intermediate goods involve substantial complementarity, but when these same varieties combine to produce final consumption, there is more substitutability. For example, computer services are today nearly an essential input into semiconductor design, banking, and health care. But computers are much more substitutable when used for final consumption - for entertainment, we can play computer games or watch television or ride bikes in the park. In order to produce within a firm, there are a number of complementary steps that must be taken. In final consumption (e.g. in utility), however, there appears to be a reasonably high degree of substitution across goods.

The remainder of the model is standard. The resource constraints for physical and human capital are

$$
\int_{0}^{1} K_{i} d i \leq K
$$

and

$$
\int_{0}^{1} H_{i} d i \leq H \equiv \bar{h} \bar{L}
$$

where $\bar{h}$ is an exogenously-given amount of human capital per worker and $\bar{L}$ is the exogenous number of workers in the economy, both constant. We do not endogenize human capital accumulation in this environment in order to keep the model as simple as possible; this could be added easily, however. Physical capital accumulates in the usual way, and investment consists of units of the aggregate final good:

$$
\dot{K}=I-\delta K, \quad K_{0} \text { given. }
$$

\footnotetext{
${ }^{7}$ An issue of timing arises here. To keep the model simple and because we are concerned with the long run, we make the seemingly strange assumption that intermediate goods are produced and used simultaneously. A better justification goes as follows. Imagine incorporating a lag so that today's final good is used as tomorrow's intermediate input. The steady state of that setup would then deliver the result we have here.
} 


$$
C+I \leq Y
$$

Finally, preferences are standard

$$
U=\int_{0}^{\infty} e^{-\lambda t} u\left(C_{t}\right) d t
$$

with $u^{\prime}(C)>0$ and $u^{\prime \prime}(C)<0$. We've dropped time subscripts from this economic environment (except in this final equation) since we will primarily be concerned with the steady state of this model.

Intermediate goods are similar to capital in that both are produced goods, in contrast to labor. The key difference is that intermediate goods fully depreciate in production, but from a long-run perspective, this does not really matter. The share of produced goods in the production of good $i$ is therefore $\alpha(1-\sigma)+\sigma$. For standard parameter values like $\alpha=1 / 3$ and $\sigma=1 / 2$, this share is $2 / 3-$ the value needed for neoclassical models to explain large income differences.

The parameter $\sigma$ measures the importance of linkages in our economy. If $\sigma=$ 0 , the productivity of physical and human capital in each variety depends only on $A_{i}$ and is independent of the rest of the economy. To the extent that $\sigma>0$, low productivity in one sector feeds back into the others. Transportation services may be unproductive in a poor country because of inadequate fuel supplies or repair services, and this low productivity will reduce output throughout the economy.

\section{A SYMMETRIC ALLOCATION OF RESOURCES}

Before turning to a competitive equilibrium in this environment, it is useful to consider a simple "rule of thumb" allocation, analogous to Solow's fixed saving rate. There are two advantages to this approach. First, it is simple, easy to solve for, and allows us to illustrate some of the key points of the model. Second, it serves as a useful benchmark when it comes time to understand why the competitive equilibrium looks the way it does. Our rule of thumb allocation is a symmetric allocation with a constant investment rate: 
Definition 1. The symmetric allocation of resources in this economy has $K_{i}=K, H_{i}=H, X_{i}=X, I=\bar{s} Y$, and $z_{i}=\bar{z} Y_{i}$, where $0<\bar{s}, \bar{z}<1$.

Under this symmetric allocation, the solution for GDP in the economy at any point in time is given in the following proposition. (Outlines of all proofs are in the Appendix.)

Proposition 1. The Symmetric Allocation, Given CAPital: Given $K$ units of capital, GDP under the symmetric allocation of resources is

$$
Y=\phi(\bar{z})\left(S_{\theta}^{1-\sigma} S_{\rho}^{\sigma}\right)^{\frac{1}{1-\sigma}} K^{\alpha} H^{1-\alpha},
$$

where

$$
S_{\rho} \equiv\left(\int_{0}^{1} A_{i}^{\rho} d i\right)^{\frac{1}{\rho}}
$$

and

$$
\phi(\bar{z}) \equiv\left((1-\bar{z})^{1-\sigma} \bar{z}^{\sigma}\right)^{\frac{1}{1-\sigma}}
$$

and $S_{\theta}$ is defined in a way analogous to $S_{\rho}$.

The model delivers a simple expression for GDP. $Y$ is the familiar CobbDouglas combination of aggregate physical and human capital with constant returns to scale.

Two novel results also emerge, and both are related to total factor productivity. The first illustrates the role of substitution versus complementarity, while the second reveals the multiplier associated with linkages through intermediate goods.

First, consider the $S_{\theta}$ and $S_{\rho}$ terms. Each is a CES combination of the underlying sectoral TFPs. Since $\theta$ is between zero and one, $S_{\theta}$ is between the geometric mean and the arithmetic mean of the TFPs. But with $\rho$ less than zero, $S_{\rho}$ ranges from the geometric mean down to the minimum of the underlying $A_{i}$, depending on the strength of complementarity. Total factor productivity for the economy as a whole depends on the geometric average of the CES terms, 
$S_{\theta}^{1-\sigma} S_{\rho}^{\sigma}$. The "substitutes" term gets a weight that equals the share of valueadded in gross output, while the "complements" term $S_{\rho}$ gets a weight that equals the intermediate goods share of gross output, $\sigma$. In other words, the importance of "weak links" in production depends on (i) the extent of complementarity and (ii) the relative importance of intermediate goods.

To interpret this result, it is helpful to consider the special case where $\theta=1$, $\rho \rightarrow-\infty$, and $\sigma=1 / 2$. In this case, TFP is the product of the average of the $A_{i}$ and the minimum of the $A_{i}$. Aggregate TFP then depends crucially on the smallest level of TFP across the sectors of the economy — that is, on the weakest link. Firms in the United States and Kenya may not differ that much in average efficiency, but if the distribution of Kenyan firms has a substantially worse lower tail, overall economic performance will suffer because of complementarity.

The second property of this solution worth noting is the multiplier associated with intermediate goods. Total factor productivity involves a multiplier, the exponent $\frac{1}{1-\sigma}>1$. A simple example should make the reason for this transparent. Suppose $Y_{t}=a X_{t}^{\sigma}$ and $X_{t}=s Y_{t-1}$; output depends in part on intermediate goods, and the intermediate goods are themselves produced using output from the previous period. Solving these two equations in steady state gives $Y^{*}=a^{\frac{1}{1-\sigma}} s^{\sigma / 1-\sigma}$, which is a simplified version of what is going on in our model. Notice that if we call $X$ "capital" instead of intermediate goods, the same formulas would apply and this looks like the neoclassical growth model with full depreciation. Intermediate goods are another source of produced inputs in a growth model.

The economic intuition for this multiplier is also straightforward. Problems in electric power generation reduces output in the banking and construction industries. This in turn hinders the financing and construction of new dams and electric power plants, further reducing output in electric power generation. Linkages between sectors within the economy generate a multiplier through which productivity problems get amplified. 
Finally, consider the role of $\phi(\bar{z})$. Differences in the allocation of resources to intermediate uses show up as aggregate TFP differences in this environment. Moreover, this term is a hump-shaped function of $\bar{z}$ which is maximized at $\bar{z}=\sigma$. Not surprisingly, this turns out to be the optimal amount of gross output to spend on intermediate goods. Departures from this optimal amount will reduce TFP.

\section{A COMPETITIVE EQUILIBRIUM WITH WEDGES}

The symmetric allocation is useful as quick guide to how the model works, but it is clearly not optimal to allocate resources symmetrically in this economy (at least as long as the $A_{i}$ differ). We turn now to a more interesting allocation, the competitive equilibrium in the presence of micro-level distortions.

This approach builds on work by Chari, Kehoe and McGrattan (2007), Restuccia and Rogerson (2007) and Hsieh and Klenow (2007), who argue that misallocation at the micro level shows up at the macro level as a reduction in aggregate TFP. Micro-level distortions can be actual formal taxes, which is how they are modeled here for simplicity. However, these wedges can also be viewed as standing in for many other possible distortions, including theft, expropriation, preferential credit arrangements, product and labor market regulations, protection from competition, and so on.

A key question that arises is this: can distortions of the magnitudes we observe generate 50-fold income differences. In simple neoclassical models, we know the answer to this question is "no." Hsieh and Klenow, for example, show that misallocations across firms within an industry reduce output by a factor of 2 or 3. What is needed is a multiplier to magnify the effects of these distortions. Intermediate goods, weak links, and superstar effects provide these multipliers, as we see next. 


\subsection{Optimization Problems}

Before defining the competitive equilibrium, it is convenient to specify the optimization problems in the economy. Letting the final output good be the numéraire, these problems are described below.

Household Problem: Taking the time path of interest rates, wages, and lump sum taxes $\left(r_{t}, w_{t}\right.$, and $\left.T_{t}\right)$ as given, and given an initial stock of assets $V_{0}$, the representative household solves

$$
\max _{\left\{C_{t}, V_{t}\right\}} \int_{0}^{\infty} e^{-\lambda t} u\left(C_{t}\right) d t
$$

subject to

$$
\dot{V}_{t}=r_{t} V_{t}+w_{t} H+T_{t}-C_{t}
$$

and subject to a no Ponzi-scheme condition.

Final Sector Problem: Taking the prices of the consumption varieties $\left\{p_{i}\right\}$ as given, a representative firm in the perfectly competitive final goods market solves at each point in time

$$
\max _{\left\{c_{i}\right\}}\left(\int_{0}^{1} c_{i}^{\theta} d i\right)^{1 / \theta}-\int_{0}^{1} p_{i} c_{i} d i .
$$

Intermediate Sector Problem: Taking the price of the intermediate varieties $\left\{p_{i}\right\}$ and the price of the aggregate intermediate good $q$ as given, a representative firm in the perfectly competitive intermediate goods market solves at each point in time

$$
\max _{\left\{z_{i}\right\}} q\left(\int_{0}^{1} z_{i}^{\rho} d i\right)^{1 / \rho}-\int_{0}^{1} p_{i} z_{i} d i
$$

VARIETy $i$ 's Problem: Taking $p_{i}, r, w, q$ and $\tau_{i}$ as given, a representative firm in the perfectly competitive variety $i$ market solves at each point in time

$$
\max _{\left\{X_{i}, K_{i}, H_{i}\right\}}\left(1-\tau_{i}\right) p_{i} A_{i}\left(K_{i}^{\alpha} H_{i}^{1-\alpha}\right)^{1-\sigma} X_{i}^{\sigma}-(r+\delta) K_{i}-w H_{i}-q X_{i} .
$$




\subsection{Defining the Competitive Equilibrium}

Definition 1. A competitive equilibrium in this economy consists of time paths for the quantities $Y, X, C, I, K, V, T,\left\{Y_{i}, K_{i}, H_{i}, X_{i}\right\},\left\{c_{i}, z_{i}\right\}$ and prices $\left\{p_{i}\right\}, q, w, r$ such that

1. $C$ and $V$ solve the Household Problem.

2. $\left\{c_{i}\right\}$ solve the Final Sector Problem.

3. $\left\{z_{i}\right\}$ solve the Intermediate Sector Problem.

4. $K_{i}, H_{i}, X_{i}$ solve the Variety $i$ Problem for all $i \in[0,1]$.

5. Markets clear:

$r$ clears the capital market: $V=K$

$w$ clears the labor market: $\int_{0}^{1} H_{i} d i=H$

$p_{i}$ clears market $i: c_{i}+z_{i}=Y_{i}$ for all $i \in[0,1]$

$q$ clears the intermediate goods market: $\int_{0}^{1} X_{i} d i=X$.

6. The government's budget is balanced: $T=\int_{0}^{1} \tau_{i} p_{i} Y_{i} d i$.

7. Other aspects of the environment hold:

$$
\begin{aligned}
& \dot{K}=I-\delta K \\
& \int_{0}^{1} K_{i} d i=K \\
& Y_{i}=A_{i}\left(K_{i}^{\alpha} H_{i}^{1-\alpha}\right)^{1-\sigma} X_{i}^{\sigma} \\
& Y=\left(\int_{0}^{1} c_{i}^{\theta} d i\right)^{1 / \theta} \\
& X=\left(\int_{0}^{1} z_{i}^{\rho} d i\right)^{1 / \rho} .
\end{aligned}
$$

Counting loosely, our competitive equilibrium involves 17 endogenous variables and specifies 17 equations to pin them down. Gross domestic product $Y$ is the numeraire in this economy, and the market for this good clears by Walras' Law (so that $C+I=Y$ is redundant).

\subsection{Solving for the Competitive Equilibrium}

We now discuss the solution of the model, beginning with a result characterizing the aggregate production of GDP at any point in time. 
Proposition 2. The COMPetitive EQUILIBRIUM, GIVEN CAPITAL: Given $K$ units of capital, GDP in the competitive equilibrium is

$$
Y=\psi(\tau)\left(Q_{\theta}^{1-\sigma} Q_{\rho}^{\sigma}\right)^{\frac{1}{1-\sigma}} K^{\alpha} H^{1-\alpha}
$$

where

$$
Q_{\rho} \equiv\left(\int_{0}^{1}\left(A_{i}\left(1-\tau_{i}\right)\right)^{\frac{\rho}{1-\rho}} d i\right)^{\frac{1-\rho}{\rho}}
$$

and

$$
\psi(\tau) \equiv \frac{1-\sigma(1-\tau)}{1-\tau} \cdot \sigma^{\frac{\sigma}{1-\sigma}}
$$

where $\tau \equiv T /(Y+q X)$ is the average tax rate in the economy, measured relative to gross output, and $Q_{\theta}$ is defined in a way analogous to $Q_{\rho}{ }^{8}$

Several insights emerge from this result. Two we can get through quickly, while the third requires more consideration. First, the multiplier associated with intermediate goods appears in exactly the same way as in the symmetric allocation, and for the same reason. This multiplier is a fundamental feature of the economy reflecting the presence of additional produced factors of production. It multiplies any distortion associated with misallocation but is not itself affected by the allocation of resources.

Second, the tax wedges affect output through TFP. Therefore, this proposition illustrates a very important result found elsewhere in the macro literature: the misallocation of resources at the microeconomic level often shows up as a reduction in TFP at the macroeconomic level. This result has been emphasized by Chari et al. (2007), Hsieh and Klenow (2007), and Restuccia and Rogerson (2007), and also plays a key role in Caselli and Gennaioli (2005) and Lagos

\footnotetext{
${ }^{8}$ The solution for $\tau$ satisfies

$$
\tau=(1-\sigma(1-\tau)) T_{\theta}+\sigma(1-\tau) T_{\rho}
$$

where $T_{\rho} \equiv \int_{0}^{1} \tau_{i}\left(\frac{A_{i}\left(1-\tau_{i}\right)}{Q_{\rho}}\right)^{\frac{\rho}{1-\rho}} d i$. That is, $T_{\rho}$ is a weighted average of the sector-specific tax rates, where the weights depend on $\rho ; T_{\theta}$ is defined analogously.
} 
(2006). Importantly, the tax wedges get multiplied by the intermediate goods multiplier. We will discuss the effect of these wedges in more detail below.

Finally, a key difference relative to the previous result on the symmetric allocation is that the curvature parameter determining the productivity aggregates has changed. For example, $\frac{\rho}{1-\rho}$ replaces the original $\rho$. Notice that if the domain of $\rho$ is $[0,-\infty)$, the range of $\frac{\rho}{1-\rho}$ is $[0,-1)$ : there is less complementarity in determining $Q_{\rho}$ than $S_{\rho}$.

This result can be illustrated with an example. Suppose $\rho \rightarrow-\infty$. In this case, the symmetric allocation depends on the smallest of the $A_{i}$, the pure weak link story. In contrast, the equilibrium allocation depends on the harmonic mean of the (tax adjusted) productivities, since $\frac{\rho}{1-\rho} \rightarrow-1$. Disasterously low productivity in a single variety is fatal in the symmetric allocation, but not in the equilibrium allocation. Why not?

The reason is that the equilibrium allocation is able to strengthen weak links by allocating more resources to activities with low productivity. If the transportation sector has especially low productivity that would otherwise be very costly to the economy, the equilibrium allocation can put extra physical and human capital in that sector to help offset its low productivity and prevent this sector from becoming a bottleneck. Of course, this must be balanced by the desire to give this sector a low amount of resources in an effort to substitute away from transportation on the consumption side. This can be seen in the math: the equilibrium solution for allocating capital is

$\frac{K_{i}}{K}=\frac{1-\tau_{i}}{1-\tau}\left[(1-\sigma(1-\tau))\left(\frac{A_{i}\left(1-\tau_{i}\right)}{Q_{\theta}}\right)^{\frac{\theta}{1-\theta}}+\sigma(1-\tau)\left(\frac{A_{i}\left(1-\tau_{i}\right)}{Q_{\rho}}\right)^{\frac{\rho}{1-\rho}}\right]$.

Another perspective on the solution is gained by returning to a special case we considered earlier. Suppose $\theta=1, \rho \rightarrow-\infty$, and $\sigma=1 / 2$, and suppose $\tau_{i}=0$. In this case, $Q_{\theta} \rightarrow \max A_{i}$ while $Q_{\rho}$ becomes the harmonic mean of the $A_{i}$. Total factor productivity is the product of the two. Contrast this with the same example for the symmetric allocation: there, TFP was the product of the arithmetic mean and the minimum. Allocating resources optimally shifts 
up both of these generalized means. The strengthening of weak links leads the minimum to be replaced by the harmonic mean. Similarly, if consumption goods enter as perfect substitutes, only the good with the highest productivity will be consumed: the arithmetic mean gets replaced by the "max," a superstar effect.

This example illustrates an intuitive way that the model can lead to large income differences across countries. Suppose a "rich" country allocates resources as in a competitive equilibrium with no taxes, but a "poor" country distorts the allocation sufficiently that it looks like the symmetric allocation. In the special case we are considering here, relative TFP between these two countries will be the product of two terms. First is the ratio of average TFP between the two countries, a standard term. But second is the ratio of the maximum TFP in the rich country to the minimum TFP in the poor country. Even if both countries have identical TFP distributions, this misallocation can lead to a large gap driven by the max-min effects associated with superstar and weak link forces. With less extreme parameter values, these forces are still in play, of course, as we will see in the numerical examples later on.

\subsection{The Steady State}

Next, we see that the long-run multiplier in the model depends on the overall share of produced factors - capital as well as intermediate goods. We get the $1 / 1-\alpha$ effect since capital accumulates in response to a change in productivity or taxes.

Proposition 3. THE COMPETITIVE EQUILIBRIUM IN STEAdY STATE: Let $y \equiv Y / \bar{L}$. The competitive equilibrium exhibits a steady state in which GDP per worker is given by

$$
y^{*}=\psi_{1}(\tau)\left(Q_{\theta}^{1-\sigma} Q_{\rho}^{\sigma}\right)^{\frac{1}{1-\sigma} \frac{1}{1-\alpha}}\left(\frac{\alpha(1-\sigma)}{\lambda+\delta}\right)^{\frac{\alpha}{1-\alpha}} \bar{h} .
$$

where $\psi_{1}(\tau) \equiv \frac{1-\sigma(1-\tau)}{1-\tau} \cdot \sigma^{\frac{\sigma}{1-\sigma} \frac{1}{1-\alpha}}$. 
Suppose we compare two economies. For reasons we can leave unspecified at the moment, sectoral TFPs are twice as high in one economy as in the other. How large are the income differences we would expect to see across these two economies, ignoring all other differences?

Let's answer this question for two worlds. The first is a standard neoclassical world where there are no intermediate goods, so $\sigma=0$. In this case, we'd expect to see income differences of $2^{3 / 2}=2.8$. Now consider a world with intermediate goods, and suppose the intermediate goods share is $\sigma=1 / 2$, a value we will justify later on. In this case, we'd expect to see much larger differences in GDP per worker in the long run. The multiplier is $\frac{1}{1-\sigma} \frac{1}{1-\alpha}=2 \times \frac{3}{2}=3$, yielding an income difference of $2^{3}=8$ times.

Another way to view this multiplier is to note that the share of produced factors in any sector's production function is $\beta \equiv \alpha(1-\sigma)+\sigma$; this is the sum of the exponent on capital and the exponent on intermediate goods. The multiplier is also equal to $\frac{1}{1-\beta}$, which is equivalent to $\frac{1}{1-\sigma} \frac{1}{1-\alpha}$.

\subsection{Symmetric Tax Wedges}

Tax wedges enter the competitive equilibrium solution in two ways. First, there is the $\psi(\tau)$ term, which is analogous to the $\phi(\bar{z})$ term in the symmetric allocation. This term captures (part of) the tradeoff between devoting resources to intermediate versus final uses. This is seen more clearly in the results below, where we first consider a symmetric tax across all sectors and then move on to study log-normally distributed tax wedges.

Proposition 4. SYMmetriC TAX WEDGES: Suppose the tax rate is iden-

tical across sectors: $\tau_{i}=\bar{\tau}$. Let $z^{*} \equiv \frac{q X}{Y+q X}$ denote the equilibrium fraction of gross output spent on intermediate goods. Then $z^{*}=\sigma(1-\bar{\tau})$, and GDP at any given point in time is

$$
Y=\left(1-z^{*}\right) z^{* \frac{\sigma}{1-\sigma}}\left(\tilde{Q}_{\theta}^{1-\sigma} \tilde{Q}_{\rho}^{\sigma}\right)^{\frac{1}{1-\sigma}} K^{\alpha} H^{1-\alpha}
$$


where

$$
\tilde{Q}_{\rho} \equiv\left(\int_{0}^{1} A_{i}^{\frac{\rho}{1-\rho}} d i\right)^{\frac{1-\rho}{\rho}},
$$

and $\tilde{Q}_{\theta}$ is defined analogously. Moreover, GDP per worker in steady state is

$$
y^{*}=\zeta_{1}(1-\sigma(1-\bar{\tau}))(1-\bar{\tau})^{\frac{1}{1-\sigma} \frac{1}{1-\alpha}-1}\left(\tilde{Q}_{\theta}^{1-\sigma} \tilde{Q}_{\rho}^{\sigma}\right)^{\frac{1}{1-\sigma} \frac{1}{1-\alpha}} \bar{h}
$$

where $\zeta_{1}$ is a collection of terms that do not depend on $\bar{\tau}$.

The first part of this proposition highlights a similarity between the competitive equilibrium with a symmetric tax and the symmetric allocation we studied earlier. The overall effect of the tax is to distort the allocation of resources between final use and intermediate use. GDP is maximized at $\bar{\tau}=0$.

The second part of the proposition shows explicitly the different effects a symmetric tax has on GDP per worker in the steady state. The first term is $1-z^{*}=1-\sigma(1-\bar{\tau})$. Notice that this term is an increasing function of the tax rate and reflects the fact that taxes lead to lower spending on intermediate goods and therefore higher spending on final uses. The second terms is the tax wedge raised to a power that depends on the overall multiplier in the model. In fact, letting $\beta$ denote the overall share of produced factors in the sectoral production function (both intermediates and capital), this second tax term can be written as $(1-\bar{\tau})^{\frac{\beta}{1-\beta}}$. The $1 / 1-\beta$ term captures the standard multiplier effects of the model. The fact that the exponent is the product of this multiplier and $\beta$ itself reflects the fact that only the fraction $\beta$ of the factors of production get distorted by a symmetric tax. In particular, the allocation of human capital across sectors is not distorted.

This raises an interesting question: if the tax is symmetric, why does it distort anything at all? The answer is that it is symmetric across sectors, but not symmetric over time. In particular, goods that are used for final uses pay the tax only once, when they are produced. However, a good devoted to intermediate uses pays the tax each time production occurs, and it is this that leads to the 
multiplier effects. This can be viewed as a simple application of the ideas in Diamond and Mirrlees (1971), Chamley (1986), and Judd (1985) regarding the taxation of intermediate goods and capital. From the long-run perspective, capital is just an intermediate good: both are produced factors of production. The distortion associated with $\bar{\tau}$ gets multiplied by the production structure of the economy.

\subsection{Random Tax Wedges}

The symmetric tax distorts the allocation of resources in an intertemporal sense, but does not otherwise distort the allocation across the sectors of the economy. As discussed in the introduction, however, one of the key ways in which weak links can be a problem in a country is if resources are misallocated across firms or sectors: electricity may be absolutely essential to production, and problems in that sector can lead to severe disruptions.

To get a sense of how misallocation across firms can matter, we suppose tax wedges and productivity levels are distributed log-normally across our continuum of sectors. In particular, we have the following result:

Proposition 5. RANDOM PRODUCTIVITY AND WEDGES: Let $a_{i} \equiv$ $\log A_{i}$ and $\omega_{i} \equiv \log \left(1-\tau_{i}\right)$ be jointly normally distributed so that $a_{i} \sim$ $N\left(\mu_{a}, \nu_{a}^{2}\right)$ and $\omega_{i} \sim N\left(\mu_{\omega}, \nu_{\omega}^{2}\right)$ and $\operatorname{Cov}\left(\omega_{i}, a_{i}\right)=\nu_{a \omega}$. Finally, let $\nu^{2} \equiv$ $\nu_{a}^{2}+\nu_{\omega}^{2}+2 \nu_{a \omega}$. Then

$\log y^{*}=\underbrace{\log \left(\frac{1-\sigma(1-\tau)}{1-\tau}\right)}_{A}+\frac{1}{1-\sigma} \frac{1}{1-\alpha}(\underbrace{(1-\sigma) \log Q_{\theta}+\sigma \log Q_{\rho}}_{B})+\zeta_{2}$

where

$A=\log \left(1-\sigma \exp \left[\mu_{\omega}+\frac{1+\rho}{1-\rho} \cdot \frac{\nu_{\omega}^{2}}{2}+\frac{\rho}{1-\rho} \nu_{a \omega}\right]\right)-\left(\mu_{\omega}+\frac{1+\theta}{1-\theta} \cdot \frac{\nu_{\omega}^{2}}{2}+\frac{\theta}{1-\theta} \nu_{a \omega}\right)$

and

$$
B=\mu_{a}+\mu_{\omega}+\left((1-\sigma) \frac{\theta}{1-\theta}+\sigma \frac{\rho}{1-\rho}\right) \cdot \frac{\nu^{2}}{2}
$$


and $\zeta_{2}$ is a collection of terms that do not depend on the wedges or productivity. Moreover, $\frac{\partial \log y^{*}}{\partial \nu_{\omega}^{2}}<0$.

GDP per person in steady state depends on two main terms, $B$ and $A$, which we discuss in turn. Term $B$ involves the CES aggregators, and notice that productivities and the tax wedges enter symmetrically: this term depends basically on the properties of $A_{i}\left(1-\tau_{i}\right)$, or, in $\operatorname{logs}, a_{i}+\omega_{i}$. Both the means and the overall variance are subject to the fundamental multiplier of the model. The variance term also depends on the degrees of substitution and complementarity, and notice that it is essentially a weighted average of the two effective curvature parameters $\frac{\theta}{1-\theta}$ and $\frac{\rho}{1-\rho}$ that enters.

Term $A$ involves only the wedges, not the productivities. It captures the offsetting effect associated with the fact that taxes reduce intermediate use and hence raise final use.

The last part of the proposition makes the important point that variation in the tax wedges across sectors unambigously reduces GDP. Efficiency, of course, requires no tax wedges at all. This result can be contrasted with the effect of variation in productivity. Changes in $\nu_{a}^{2}$ have an ambiguous effect. From the standpoint of final uses, a higher variance is a good thing. For example (loosely speaking), if goods were perfect substitutes in consumption, only the good with the highest productivity would be consumed, and a higher variance increases the highest productivity. From the standpoint of intermediate goods, however, the opposite is true.

\section{DEVELOPMENT ACCOUNTING}

To what extent can this model with intermediate goods, complementarity, and superstar effects explain income differences across countries? In this section, we attempt to quantify the mechanisms at work in our theory.

In the analysis that follows, some key parameters - such as the intermediate goods share — are calibrated quite precisely, while others — such as the degree 
of complementarity or the precise nature of micro-level distortions — are known with much less precision. The robust result that emerges from these quantitative exercises is that intermediate goods, complementarity, and superstar effects can substantially magnify income differences relative to the standard neoclassical growth model, even with quite conservative choices for the parameter values.

\subsection{Measuring the Intermediate Goods Share, $\sigma$}

For reasons that have already been explained, the crucial parameter of the model for explaining large income differences across countries is the intermediate goods share, $\sigma$. Fortunately, there is detailed empirical evidence about the magnitude of this parameter.

Basu (1995) recommends a value of 0.5 based on the numbers from Jorgenson, Gollop and Fraumeni (1987) for the U.S. economy between 1947 and 1979. Ciccone (2002), citing the extensive analysis in Chenery, Robinson and Syrquin (1986), observes that the intermediate goods share at least sometimes rises with the level of development. However, the numbers cited for South Korea, Taiwan, and Japan in the early 1970s are all substantially higher than conventional U.S. estimates, ranging from $61 \%$ to $80 \%$.

Fortunately, there are very rich data sets on input-output tables for many countries. For example, the OECD Input-Ouput database now covers 37 countries (including 9 non-OECD countries) at the level of 48 industries for a year close to 2000; see Yamano and Ahmad (2006). Historical data are available for a number of these countries as well. Using the summary tables in Yamano and Ahmad (2006) one can calculate intermediate good shares of gross output for different countries. For the United States, Japan, and India, these shares are all about $46 \%$. For China, the share is $64 \%$. Across 21 countries (mostly OECD, but including Brazil, China, and India as well), the average intermediate goods share is $52.4 \%$, with a standard deviation of about $6 \%$. These numbers are discussed in greater detail in Jones (2007a). Given all of this evidence, we take $\sigma=1 / 2$ as a benchmark value. 
TABLE 1.

Baseline Parameter Values

\begin{tabular}{ccl}
\hline Parameter & Value & Comment \\
\hline$\sigma$ & $1 / 2$ & Intermediate goods share of gross output \\
$\alpha$ & $1 / 3$ & Conventional value for capital share \\
$\bar{h}^{r} / \bar{h}^{p}$ & 2 & Standard contribution from education \\
$\theta$ & $1 / 1.2$ & Consistent with $20 \%$ markups \\
$\rho$ & -1 & Elasticity of substitution is $1 / 2$ \\
$\bar{A}^{r}$ & 1 & Normalization \\
$\bar{A}^{p}$ & $\{1,1 / 2\}$ & Illustrative purposes \\
$\gamma^{r}$ & 2 & Gives a $90 / 10$ ratio of 4.96 \\
$\gamma^{p}$ & $\{2,2.87\}$ & Doubles the $90 / 10$ ratio \\
$\bar{\tau}_{0}$ & 0.9 & Maximum tax rate \\
$\xi$ & $\cdots$ & To match capital-output ratio factor of 3 \\
\hline
\end{tabular}

Note: Robustness to these baseline values is explored below. Values for $\xi$ vary according to the simulation. In the baseline case, the values are 0.994 and 1.112 for Scenarios 3 and 4 below.

\subsection{Other Parameter Values}

The baseline parameter values we use are summarized in Table 1. Robustness checks will consider departures from these values. We pick $\alpha=1 / 3$ to match the empirical evidence on capital shares; see Gollin (2002), who shows that capital shares across countries have a mean of $1 / 3$ and are uncorrelated with GDP per worker. Rather than modeling differences in human capital we simply assume that across the richest and poorest countries, these differences contribute a factor of 2 to income differences. ${ }^{9}$

For the substitution elasticity, we take as our baseline value an elasticity of substitution in consumption of $1 / 1-\theta=6$, so that $1 / \theta=1.2$; in a model with monopolistic competition, this elasticity would deliver markups on the order of $20 \%$. This value is consistent with the extensive estimates provided by Broda and Weinstein (2006). For the complementarity parameter $\rho$, we assume $\rho=-1$, which delivers an elasticity of substitution among intermediate goods

\footnotetext{
${ }^{9}$ This factor of 2 is consistent with Klenow and Rodriguez-Clare (1997) and Hall and Jones (1999). Earlier versions of this paper endogenized human capital using a Mincerian model of schooling that allowed individuals to choose the number of years they attended school so as to maximizes their expected lifetime income; see Jones (2007b). This approach can easily rationalize the factor of 2 that is assumed for the neoclassical effects.
} 
of $1 / 2$, midway between Leontief and Cobb-Douglas. There is very little solid information about this parameter and we will carefully explore robustness to other values in what follows.

For understanding how the model works, it proves useful to let taxes and productivity be deterministic functions of the variety index $i$ (as opposed to assuming they are log normally distributed, for example). In particular, we assume the following functions:

$$
\begin{gathered}
A_{i}=\bar{A} e^{-\gamma i} \\
\tau_{i}=\left\{\begin{array}{cc}
\bar{\tau}_{0}+1-e^{\xi i} & i \in[0,1 / 2] \\
\tau_{1-i} & i \in(1 / 2,1]
\end{array}\right.
\end{gathered}
$$

We normalize the order of varieties so that productivity decreases with the index $i$; moreover, we assume this occurs exponentially. Taxes are a symmetric "v"shaped function of variety, with high tax rates of $\bar{\tau}_{0}$ at the ends and a low tax rate in the middle. The advantage of this structure is that both superstar and weak link problems appear: resources are allocated away from the superstar and weakest links and towards mid-productivity sectors. The remaining parameters in the table pin down these productivities and tax wedges.

Four parameters $-\bar{A}^{r}, \bar{A}^{p}, \gamma^{r}$, and $\gamma^{p}-$ characterize the distibution of TFPs across varieties. One source of information about these parameters is Hsieh and Klenow (2007). Hsieh and Klenow measure firm-level TFP within 4-digit manufacturing sectors for China, India, and the United States. They find that the 90/10 ratios of firm-level TFP (in a value-added production function) are about 16 for the United States, 12 for China, and 31 for India. These statistics do not correspond exactly to what we want for our model. We'd like to see the variation across all firms and sectors in the economy. For example, the weak link story involves electricity, transportation, replacement parts, machine tools, etc. - inputs that are taken from different sectors of the economy. We'd also like some sense of differences in things like property rights and corruption. Moreover, the mapping between their value-added TFP and our gross-output 
TFP is not entirely clear. ${ }^{10}$ Finally, measurement problems may lead Hsieh and Klenow to overstate TFP differences across firms.

Still, these are useful observations to get us started. Based on these numbers, we consider a conservative choice of parameter values. We normalize $\bar{A}^{r}=1$, and consider two alternatives for $\bar{A}^{p}$ : that it equals one as well and that it takes a value of $1 / 2$. For the decay rate across varieties, we pick $\gamma^{r}=2$, so that the $90 / 10$ ratio for our rich country is only 4.96 . For the poor country, we will sometimes use this same value, so that both countries have the same distribution of TFP. Alternatively, we will consider $\gamma^{p}=2.87$, which leads the poor country to have a 90/10 ratio that is twice as high as the rich country (as in the U.S.-India comparison in Hsieh and Klenow). Future work on productivity differences across sectors could potentially shed better light on these parameter values. Figure 2 shows these different productivity scenarios.

Finally, we need to parameterize the tax differences across countries. For the rich country, we assume $\tau_{i}^{r}=0$ so there are no distortions. For the poor country, we have two parameters describing taxes, the maximum tax rate $\bar{\tau}_{0}$ and the decay rate $\xi$. Since capital can be viewed as an intermediate good, the capital-output ratio contains information about taxes. In particular, our model implies

$$
\kappa \equiv\left(\frac{K}{Y}\right)^{*}=\frac{\alpha(1-\sigma)}{\lambda+\delta} \cdot \frac{1-\tau}{1-\sigma(1-\tau)} .
$$

That is, the capital-output ratio depends on the average tax share collected in the economy. Capital-output ratios and investment rates vary by something like a factor of 3 across countries. This implies a value of $\tau^{p}=1 / 2$ (assuming $\sigma=1 / 2$ ). Note that $\tau^{p}$ is an endogenous variable, not a parameter. We assume the maximum tax rate $\bar{\tau}_{0}$ is $90 \%$, and choose the decay rate $\xi$ to match the average share of tax revenues of $1 / 2$.

Figure 3 shows the assumed tax wedges in the poor country (for one key scenario below). Notice that distortions are highest for the most and least

\footnotetext{
${ }^{10}$ Simple models can lead one to see this difference as undoing the multiplier. In this model, however, the standard deviation of value-added TFP and the standard deviation of gross-output TFP across firms is equal (in the absence of tax wedges).
} 


\section{FIGURE 2. Assumed Productivities}

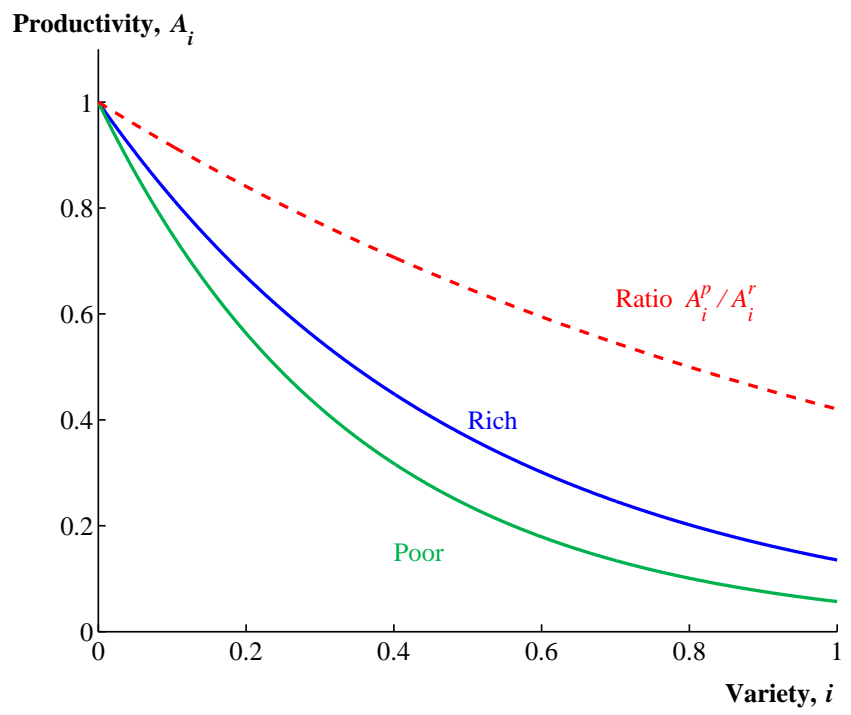

Note: In some simulations, we assume the rich and poor country have the same productivity levels (indicated by the "Rich" curve). In others, we let the 90/10 ratio for the "Poor" country be twice as large as for the "Rich" country. 
FIGURE 3. Assumed Tax Wedges (Scenario 4)

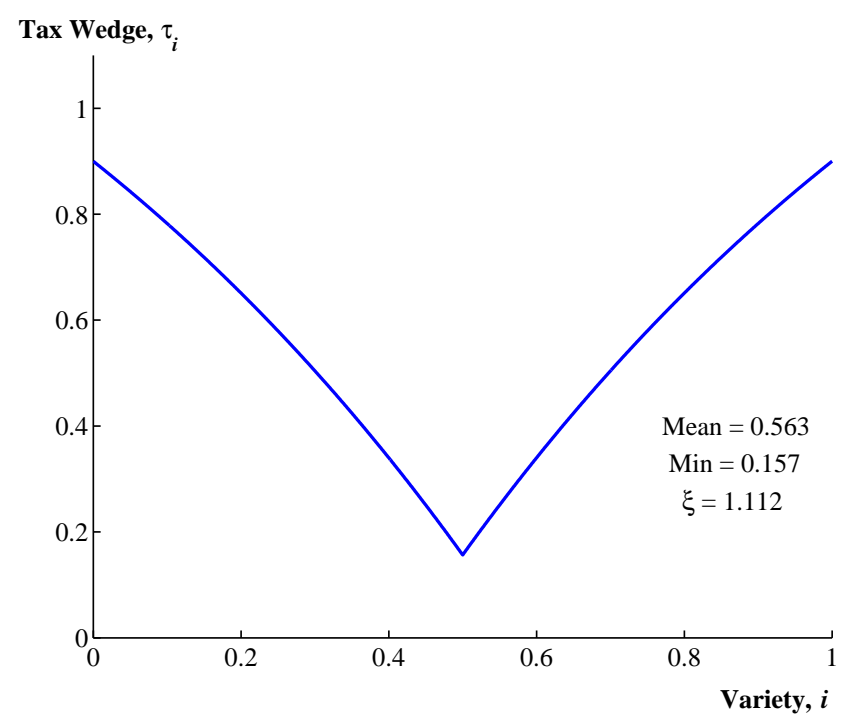

Note: The graph shows the tax wedges for Scenario 4 below. The maximum tax rate at the end points is $\bar{\tau}_{0}=0.90$. The decay rate $\xi$ is chosen to deliver a tax share of gross output of $1 / 2$, reducing the capital-output ratio by a factor of 3 in the poor country. Tax schedules look similar in other scenarios. 
TABLE 2.

Output per Worker Ratios: Quantitative Examples

\begin{tabular}{|c|c|c|c|c|c|}
\hline \multirow[b]{2}{*}{ Scenario } & \multirow[b]{2}{*}{ Baseline } & \multicolumn{3}{|c|}{ — Substitution \& Complementarity - } & \multirow{2}{*}{$\begin{array}{r}\text { No Interme- } \\
\text { diate Goods } \\
\sigma=0\end{array}$} \\
\hline & & $\theta=1 / 1.1$ & $\theta=1 / 1.3$ & $\rho=-100$ & \\
\hline Benchmark: & 5.3 & 5.3 & 5.3 & 5.3 & 3.5 \\
\hline 1. $A_{i}^{r} / A_{i}^{p}=2$ & 42.7 & 42.7 & 42.7 & 42.7 & 9.8 \\
\hline 2. $A_{p} 90 / 10$ twice as high & 12.9 & 12.3 & 13.6 & 14.4 & 3.9 \\
\hline 3. Tax wedges in poor & 19.6 & 25.0 & 16.8 & 22.4 & 6.3 \\
\hline 4. $(2+3) 90 / 10$ shift + taxes & 53.2 & 63.9 & 47.7 & 72.9 & 7.9 \\
\hline 5. $(1+3) A_{i}^{r} / A_{i}^{p}=2+$ taxes & 156.5 & 200.1 & 134.2 & 178.9 & 17.8 \\
\hline
\end{tabular}

Note: The table reports income ratios between rich and poor countries under various scenarios. The benchmark case has no TFP differences across countries and a constant tax rate across varieties, so only the neoclassical factors appear - a difference of 2 from human capital and a difference of $\sqrt{3}$ from the capital-output ratio; so with $\sigma=0$, the differences is $2 \times \sqrt{3} \approx 3.5$. The last column shows the results when the intermediate goods share is zero (and where $\rho=-1$ ). (In solving numerically, we evaluate the integrals as summations over 1001 grid points.)

productive sectors. This will give rise to superstar and weak link problems.

\subsection{Quantitative Analysis}

Table 2 shows the quantitative results for the model. It is easiest to begin in the upper right portion of the table, which shows the baseline case when the intermediate goods share is zero.

The benchmark case features $A_{i}$ 's that vary across sectors but which are identical in the rich and poor country. The rich country features no tax wedges, while the poor country has $\tau_{i}=1 / 2$, so the wedges do not vary across sectors. This overall tax and the 2-fold difference in human capital are the only sources of income differences in the benchmark case. As shown in the table, when the intermediate goods share is zero, these differences lead to an income ratio of 3.5 between the rich and poor countries. This value is equal to the 2-fold human capital difference multiplied by the $\sqrt{3}$ contribution from the tax rate, working through the capital-output ratio. The other columns of the table show how this 
effect gets amplified when intermediate goods are distorted, as well as capital, leading to a 5.3-fold income difference.

Scenario 1 introduces an extra 2 -fold difference in the $A_{i}$ between the rich and poor countries to illustrate some basic forces in the model. This difference could arise from technological differences, or could simply reflect theft. Under the theft interpretation, $50 \%$ of output gets stolen any time a good is produced.

In the pure neoclassical framework with no intermediate goods, this 2-fold difference in TFP amplifies the income differences by $2^{1 / 1-\alpha}=2^{3 / 2} \approx 2.8$ to yield a difference of 9.8. The other columns illustrate the power of the intermediate goods multiplier. The TFP difference now amplifies income differences by $2^{\frac{1}{1-\sigma} \frac{1}{1-\alpha}}=2^{2 \times 3 / 2}=2^{3}=8$, yielding a much larger income difference of 42.7. The intuition is that the "theft tax" gets paid repeatedly when intermediate goods are involved: $1 / 2$ of the steel is stolen from the steel plant, $1 / 2$ of the cars are stolen from the automobile plant, and $1 / 2$ of the pizzas get stolen from the pizza delivery service. In this sense, the steel gets stolen three times rather than just once, and this is the intermediate goods multiplier.

The remaining scenarios explore the roles of weak links and superstar effects in this environment. Scenario 2 shows the competitive equilibrium allocation of resources with no variation in taxes, but this time allows the 90/10 ratio to be twice as wide in the poor country as in the rich country (as shown back in Figure 2). By itself, this change leads to relatively small income differences, in part because the competitive equilibrium shuffles resources around to strengthen weak links and take advantage of superstar varieties.

Scenario 3 returns to the case where the rich and poor countries have identical $A_{i}$ but this time allows tax wedges to distort the allocation of resources in the poor country. In the absence of the intermediate goods multiplier, these tax wedges increase the income ratio from 3.5 to 6.3. In the baseline case, the presence of intermediate goods raises this ratio to 19.6. This ratio gets increased further to 25.0 in the case where the elasticity of substitution among consumption goods is higher $(\theta=1 / 1.1)$ : the higher is this elasticity, the more 
FIGURE 4. Scenario 4: Taxes and Allocations

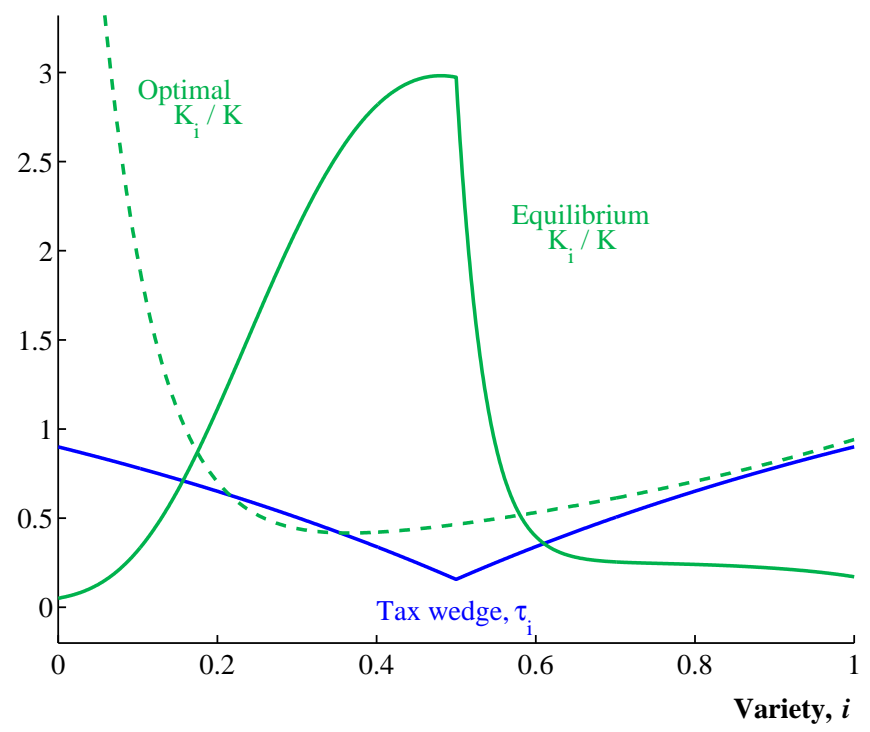

Note: The " $v$ "-shaped tax wedges distort the resource allocation away from both the superstar sectors and the weak link sectors.

costly are tax distortions, as they push the allocation away from the superstar varieties.

While the other scenarios have considered one change at a time away from the baseline case in the first row, Scenario 4 combines the two changes in Scenarios 2 and 3. Tax wedges vary across sectors (as shown in Figure 3), and now the 90/10 ratio of $A_{i}$ in the poor country is twice as wide as in the rich (as in Figure 2), so the distortions are even more costly. A neoclassical difference of 7.9 (for $\sigma=0$ ) gets amplified to 53.2 in the baseline case. With a higher elasticity of substitution among consumption, superstar effects raise this to 63.9. With extreme complementarity $(\rho=-100)$, weak link forces deliver an income ratio of 72.9 .

Figure 4 shows the effect of these tax wedges on the allocation of resources in the poor country. The dark (blue) line shows the tax wedge for each variety, which we have already seen in an earlier figure. The lighter (green) lines reveal 
the allocation of resources. The solid one plots the equilibrium allocation of $K_{i} / K$ across varieties, while the dashed line shows the optimal allocation. These differ sharply. The "v"-shaped tax wedge distorts the allocation away from both the highly-productive sectors and the least-productive sectors. At high productivities, the superstar sectors are harmed, which has a large effect on output. At low productivities, the weakest links are not strengthened, which again has a large effect on output. Together with the general multiplier associated with intermediate goods, these forces explain why the model is able to deliver such large income differences from relatively small productivity differences and small tax distortions.

Finally, Scenario 5 in Table 2 is a simple way of illustrating that it is easy to get even larger income differences in this model; the earlier scenarios in the table are by no means extreme. In Scenario 5, we assume productivities in the poor country are half the level of productivities in the rich country and allow the " $v$ "-shaped tax wedges to distort the allocation of resources. Income ratios of 150 or more are possible in this scenario. Similarly large differences can be achieved in other ways, such as by letting the variation in $A_{i}$ across varieties be even larger.

\subsection{Summary}

Some of the parameters of the model - like the intermediate goods share and the capital share - are quite precisely pinned down by empirical evidence. Others - like the strength of substitution and complementarity and the extent and nature of resource misallocation - are known with much less precision.

The point of these numerical examples is not to claim that they precisely characterize the nature of income differences between the richest and poorest countries. Rather, they illustrate that these mechanisms are able to generate enormous differences using relatively conservative choices of parameter values.

Fortunately, the high value of the intermediate goods share by itself goes a long way toward helping us understand large income differences across countries. The aggregate productivity index $Q$ may differ by a factor of 2 for many 
reasons: distortions to technology adoption, complementarity and weak links, or the misallocation of resources. Whatever the cause, the intermediate goods multiplier leads relatively small and plausible differences in $Q$ to magnify into large income differences across countries. The economics of this magnification is quite intuitive. Because of linkages across sectors, the misallocation of resources in one sector affects output in others, which in turn feeds back into the original sector.

\section{THE CUMULATIVE EFFECT OF REFORMS}

The model possesses two key features that seem desirable in any theory designed to explain the large differences in incomes across countries. First, relatively small and plausible differences in underlying parameters can yield large differences in incomes. That is, the model generates a large multiplier.

The second feature is one we explore now. Despite this large multiplier, reforms that eliminate the tax wedges may have relatively small effects on output. If a chain has a number of weak links, fixing one or two of them will not change the overall strength of the chain.

This principle is clearly true in the extreme Leontief case, but it holds more generally as well. To see this, consider a simple exercise. Suppose the economy is characterized by Scenario 3 above: it has the "v"-shaped tax wedges but is otherwise identical to the richest country in the world, apart from a 2-fold difference in human capital. A sequence of reforms then eliminates the tax wedges one at a time. As was shown in Table 2, our poor country begins with an income about 1/20th of that in the rich country. For this exercise, we approximate the continuum of varieties with a 300-point grid, so after 300 reforms, the poor country will have an income of $1 / 2$ the rich country, due only to the human capital difference. The question is this: what does the transition path look like as the economy undergoes these reforms?

Figure 5 shows the sequence of steady states that results from several different paths of reform. The "best path" solves for the reform in each period that 


\section{FIGURE 5. The Cumulative Effect of Reforms}

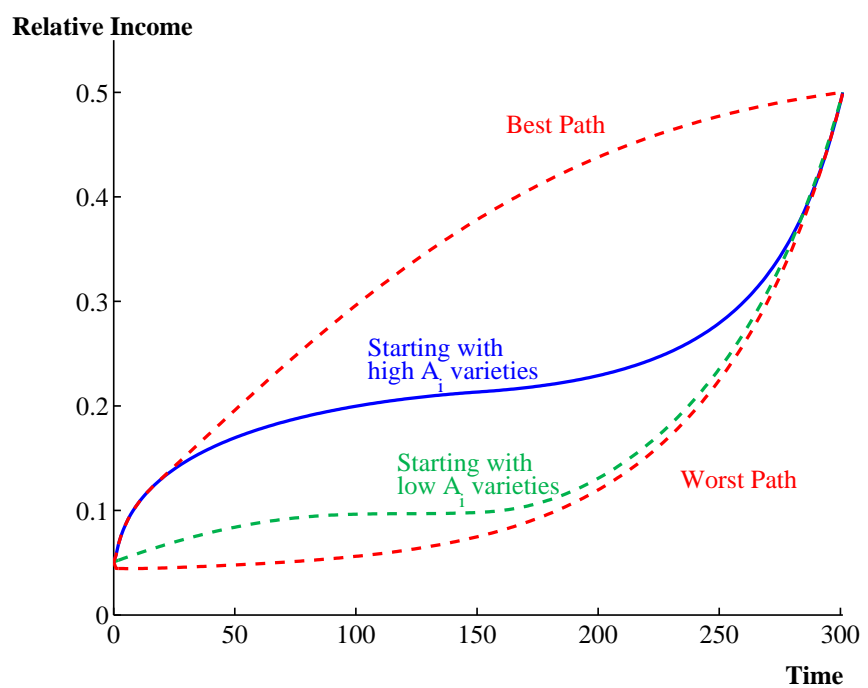

Note: The economy is initially characterized as in Scenario 3, where we approximate the continuum of varieties with a 300-point grid. Each period, one of the tax wedges is eliminated. The plot shows the sequence of steady states that result, depending on the nature of the reform process. 
increases output by the most. The "worst path" finds the reform that increases output by the least. The other two paths start with either $i=0$ (the most productive sector) or $i=1$ (the least productive sector) and proceed sequentially across the varieties.

The key point of the figure is that three of the four paths considered feature long, flat regions - substantial periods of reform that have relatively small impacts on incomes. For example, for the "worst path" reforms, the first doubling of incomes does not occur until nearly $60 \%$ of the sectors are reformed; the second doubling occurs much more rapidly, by the $80 \%$ reform point.

It is interesting to compare the two paths in the middle, which proceed by reforming the most productive versus least productive sectors first. Initially, reforming the most productive sectors has a large effect on output: these are some of the most distorted sectors, and because of the role of high substitution in consumption, reforms to a superstar sector can increase output substantially. However, once a few superstar sectors are fixed, subsequent gains are harder to come by: the weak link sectors are reformed last, and these exert a substantial negative effect on output.

Starting with the least productive sectors leads to a different pattern. Because of complementarity, fixing a few weak links has relatively small effects on output. When the economy suffers from many problems, reforms that address only a few may have small effects. The large output gains at the end result from the superstar distortions being removed.

Interestingly, the sharp curvature of these paths suggests that the pressure for reform can accelerate. This general setup may then help us to understand why some countries remain unreformed and poor for long periods while others those that are close to the cusp - experience growth miracles.

Hausmann, Rodrik and Velasco (2005) advocate studying all of the distortions in an economy and quantifying the output gains from relaxing each distortion. Clearly, such an approach would work well in this environment - this leads to the "best path" of reforms. This paper emphasizes the interactions across 
distortions. In particular, reforms in poor countries can "fail" because numerous other distortions keep output low. Politically, it seems important to recognize that valuable reforms can have small impacts until other complementary reforms are undertaken, at least unless the sequence of reforms is chosen quite carefully.

Of course, it should also be recognized that some reforms could affect distortions in multiple sectors simultaneously. One example of this is considered next.

\subsection{Multinationals and Trade}

Multinational firms and international trade may help to solve these problems if they are allowed to operate. For example, multinationals may bring with them knowledge of how to produce, access to transportation and foreign markets, and the appropriate capital equipment. Indeed many of the examples we know of where multinationals produce successfully in poor countries effectively give the multinational control on as many dimensions as possible: consider the maquiladoras of Mexico and the special economic zones in China and India. Countries may specialize in goods they can produce with high productivity and, to the extent possible, import the goods and services that suffer most from weak links. ${ }^{11}$

On the other hand, domestic weak links may still be a problem. A lack of contract enforcement may make intermediate inputs hard to obtain. Knowledge of which intermediate goods to buy and how to best use them in production may be missing. Weak property rights may lead to expropriation. Inadequate energy supplies and local transportation networks may reduce productivity. The right goods must be imported, and these goods must be distributed using local resources and nontradable inputs, as in Burstein, Neves and Rebelo (2003).

Incorporating international trade into this framework is a natural direction for future research. Of course, to the extent that these channels are shut down in the

\footnotetext{
${ }^{11}$ Nunn (2007) provides evidence along these lines, suggesting that countries that are able to enforce contracts successfully specialize in goods where contract enforcement is critical. See also Grossman and Maggi (2000) and Waugh (2007).
} 
poorest countries of the world, the closed economy benchmark considered here illustrates the range of income differences that could exist. But the transition dynamics that would result from opening up to trade or multinationals could be different from the reform paths highlighted above.

\section{CONCLUSION}

In this theory of economic development, relatively small average differences across countries translate into large differences in aggregate output per worker. There are two reasons for this. First, forces of complementarity and substitution lead extreme sectors — both the superstars and weak links — to play disproportionate roles. Because of misallocation, income differences between countries can be driven by opposite extremes. Income in the rich countries may depend primarily on superstars, while income in the poor countries may depend on the weakest links.

The second amplification force is even simpler and easier to quantify. The presence of intermediate goods leads to a multiplier that depends on the share of intermediate goods in gross output. Distortions to the transportation sector reduce the output of many other sectors, including truck manufacturing and the fuel sector. This in turn will reduce output in the transportation sector. This vicious cycle is the source of the multiplier associated with intermediate goods.

An important channel for future research concerns the role of intermediate goods. The present model simplifies considerably by taking the intermediate input to be units of the final output good. The input-output matrix in this model is very special. This is a good place to start. However, it is possible that the rich input-output structure in modern economies delivers a multiplier smaller than $\frac{1}{1-\sigma}$ because of "zeros" in the matrix. In work in progress, Jones (2007a) explores this issue. The preliminary results are encouraging. For example, if the share of intermediate goods in each sector is $\sigma$ but the composition of this share varies arbitrarily, the aggregate multiplier is still $\frac{1}{1-\sigma}$. More generally, I plan to use actual input-output tables for both OECD and developing countries 
to compute the associated multipliers. I believe this will confirm the central role played by intermediate goods in amplifying distortions.

\section{APPENDIX： PROOFS OF THE PROPOSITIONS}

Proposition 1. The SYMmetric AlLOCATION, Given CAPITAL:

Proof. Follows directly from the fact that $Y_{i}=A_{i} m$, where $m=$ $\left(K^{\alpha} H^{1-\alpha}\right)^{1-\sigma} X^{\sigma}$ is constant across activities.

Proposition 2. The COMPETITIVE Equilibrium, GIVEN CAPITAL:

Proof.

1. The first order conditions from the Variety $i$ Problem are

$$
\begin{gathered}
\left(1-\tau_{i}\right) p_{i} \alpha(1-\sigma) \frac{Y_{i}}{K_{i}}=r+\delta \\
\left(1-\tau_{i}\right) p_{i}(1-\alpha)(1-\sigma) \frac{Y_{i}}{H_{i}}=w \\
\left(1-\tau_{i}\right) p_{i} \sigma \frac{Y_{i}}{X_{i}}=q .
\end{gathered}
$$

Substituting these conditions back into the production function yields an equation that characterizes the price of $\operatorname{good} i$ :

$$
p_{i}=\frac{m c}{A_{i}\left(1-\tau_{i}\right) \epsilon},
$$

where $m c \equiv\left((r+\delta)^{\alpha} w^{1-\alpha}\right)^{1-\sigma} q^{\sigma}$ is a key piece of the marginal cost and $\epsilon \equiv\left(\alpha^{\alpha}(1-\alpha)^{1-\alpha}\right)^{1-\sigma}(1-\sigma)^{1-\sigma} \sigma^{\sigma}$.

2. Integrating the Variety $i$ first order conditions above gives

$$
\begin{gathered}
(r+\delta) K=\alpha(1-\sigma) \int\left(1-\tau_{i}\right) p_{i} Y_{i} d i \\
w H=(1-\alpha)(1-\sigma) \int\left(1-\tau_{i}\right) p_{i} Y_{i} d i \\
q X=\sigma \int\left(1-\tau_{i}\right) p_{i} Y_{i} d i
\end{gathered}
$$


where the limits of the integration are understood to be 0 to 1 . Note that

$$
\int p_{i} c_{i} d i=Y, \int p_{i} z_{i} d i=q X, \int p_{i} Y_{i} d i=Y+q X .
$$

Define $\tau \equiv \frac{T}{Y+q X}$ to be tax revenues as a share of gross output. Then

$$
\int\left(1-\tau_{i}\right) p_{i} Y_{i} d i=(1-\tau)(Y+q X) .
$$

Substituting this expression into (A.2), (A.3), and (A.4) gives

$$
\begin{gathered}
(r+\delta) K=\alpha(1-\sigma) \frac{1-\tau}{1-\sigma(1-\tau)} Y \\
w H=(1-\alpha)(1-\sigma) \frac{1-\tau}{1-\sigma(1-\tau)} Y \\
q X=\frac{\sigma(1-\tau)}{1-\sigma(1-\tau)} Y .
\end{gathered}
$$

These expressions allow us to solve for $m c$ (see the definition under (A.1)) as

$$
m c=\frac{1-\tau}{1-\sigma(1-\tau)} \cdot \epsilon \cdot \frac{Y}{\left(K^{\alpha} H^{1-\alpha}\right)^{1-\sigma} X^{\sigma}} .
$$

3. Next, consider the first-order conditions from the Final Good and Intermediate Good Problems. For each of these problems, take the first order condition and then integrate it back into the firm's production function. For the final good, this gives

$$
\left(\int p_{i}^{-\frac{\theta}{1-\theta}} d i\right)^{-\frac{1-\theta}{\theta}}=1
$$

and for the intermediate good

$$
\left(\int p_{i}^{-\frac{\rho}{1-\rho}} d i\right)^{-\frac{1-\rho}{\rho}}=q
$$

Now substitute (A.1) into (A.9) to get

$$
m c=\epsilon Q_{\theta}
$$

where

$$
Q_{\theta} \equiv\left(\int_{0}^{1}\left(A_{i}\left(1-\tau_{i}\right)\right)^{\frac{\theta}{1-\theta}} d i\right)^{\frac{1-\theta}{\theta}}
$$


Combining (A.1) with this expression, we can solve (A.10) to find

$$
q=\frac{Q_{\theta}}{Q_{\rho}}
$$

where $Q_{\rho}$ is defined analogously to $Q_{\theta}$. Combining (A.8), (A.11), (A.7), and (A.13) yields the main result in the proposition.

4. Finally, we need to solve for $\tau$. From the first-order conditions for the Final Goods Problem and the Intermediate Goods Problem we get

$$
p_{i} Y_{i}=p_{i} c_{i}+p_{i} z_{i}=p_{i}^{-\frac{\theta}{1-\theta}} Y+\left(p_{i} / q\right)^{-\frac{\rho}{1-\rho}}(q X)
$$

Multiplying this expression by $\tau_{i}$, integrating, and then using (A.1), (A.11), and (A.13) leads to the solution for $\tau$ given implicitly in footnote 8 .

Proposition 3. THE COMPETITIVE EQUILIBRIUM IN STEAdy STATE:

Proof. Straightforward using (A.5) and the Euler equation from the Household Problem.

Proposition 4. Symmetric tax WedGes:

Proof. Straightforward evaluation given earlier results.

Proposition 5. RANDOM PRODUCTIVITY AND WEDGES:

\section{Proof.}

1. Define $Q(\eta) \equiv\left(\int\left(A_{i}\left(1-\tau_{i}\right)\right)^{\eta} d i\right)^{1 / \eta}$. Define $m_{i} \equiv \eta\left(a_{i}+\omega_{i}\right)$. Then $m_{i} \sim N\left(\eta\left(\mu_{m}+\mu_{a}\right), \eta^{2} \nu^{2}\right)$. Therefore,

$$
\begin{aligned}
Q(\eta) & =\left(E\left(e^{m_{i}}\right)\right)^{1 / \eta} \\
& =e^{\mu_{a}+\mu_{\omega}+\frac{1}{2} \eta \nu^{2}} .
\end{aligned}
$$

Let $Q \equiv\left[Q\left(\frac{\theta}{1-\theta}\right)\right]^{1-\sigma}\left[Q\left(\frac{\rho}{1-\rho}\right)\right]^{\sigma}$. Then

$$
\log Q=\mu_{a}+\mu_{w}+\frac{1}{2} \cdot\left((1-\sigma) \frac{\theta}{1-\theta}+\sigma \frac{\rho}{1-\rho}\right) \nu^{2}
$$

which is term $B$ of the proposition. 
2. To get term $A$, we need to solve for $\tau$. From footnote 8 , one can obtain

$$
1-\tau=\frac{1-T_{\theta}}{1-\sigma\left(T_{\theta}-T_{\rho}\right)} .
$$

Evaluating the integrals in $T_{\theta}$ and $T_{\rho}$ as above gives

$$
T_{\theta}=1-\exp \left\{\mu_{\omega}+\frac{1}{2} \cdot \frac{1+\theta}{1-\theta} \nu_{\omega}^{2}+\frac{\theta}{1-\theta} \nu_{a \omega}\right\}
$$

and $T_{\rho}$ is the analogous expression. These expressions deliver term $A$.

\section{REFERENCES}

Acemoglu, Daron and James Robinson, Economic Origins of Dictatorship and Democracy, Cambridge University Press, 2005.

— and Simon Johnson, "Unbundling Institutions," Journal of Political Economy, October 2005, 113, 949-995.

_ , _ , and James A. Robinson, "The Colonial Origins of Comparative Development: An Empirical Investigation,” American Economic Review, December 2001, 91 (5), 1369-1401.

Armenter, Roc and Amartya Lahiri, "Endogenous Productivity and Development Accounting," 2006. University of British Columbia working paper.

Basu, Susanto, "Intermediate Goods and Business Cycles: Implications for Productivity and Welfare," American Economic Review, June 1995, 85 (3), 512-531.

Becker, Gary S. and Kevin M. Murphy, "The Division of Labor, Coordination Costs, and Knowledge," Quarterly Journal of Economics, November 1992, 107 (4), 1137 1160.

Benabou, Roland, "Heterogeneity, Stratification and Growth: Macroeconomic Implications of Community Structure and School Finance," American Economic Review, June 1996, 86 (3), 584-609.

Blanchard, Olivier and Michael Kremer, "Disorganization," The Quarterly Journal of Economics, November 1997, 112 (4), 1091-1126.

Broda, Christian and David E. Weinstein, "Globalization and the Gains from Variety," The Quarterly Journal of Economics, May 2006, 121 (2), 541-585.

Burstein, Ariel, Joao Neves, and Sergio Rebelo, "Distribution Costs and Real Exchange Rate Dynamics," Journal of Monetary Economics, September 2003, 50, 1189-1214.

Caselli, Francesco and Nicola Gennaioli, "Dynastic Management,” December 2005. London School of Economics working paper. 
— and Wilbur John Coleman, "The World Technology Frontier," American Economic Review, June 2006, 96 (3), 499-522.

Chamley, Christophe, "Optimal Taxation of Capital Income in General Equilibrium with Infinite Lives," Econometrica, May 1986, 54 (3), 607-622.

Chari, V.V., Pat Kehoe, and Ellen McGrattan, "The Poverty of Nations: A Quantitative Investigation,” 1997. Working Paper, Federal Reserve Bank of Minneapolis.

__ _ _ , and _ , "Business Cycle Accounting," Econometrica, May 2007, 75 (3), 781-836.

Chenery, Hollis B., Sherman Robinson, and Moshe Syrquin, Industrialization and Growth: A Comparative Study, New York: Oxford University Pres, 1986.

Ciccone, Antonio, "Input Chains and Industrialization," Review of Economic Studies, July 2002, 69 (3), 565-587.

Conley, Timothy G. and Bill Dupor, "A Spatial Analysis of Sectoral Complementarity," Journal of Political Economy, April 2003, 111 (2), 311-352.

Diamond, Peter A. and James A. Mirrlees, "Optimal Taxation and Public Production I: Production Efficiency," American Economic Review, March 1971, 61 (1), 8-27.

Dixit, Avinash K. and Joseph E. Stiglitz, "Monopolistic Competition and Optimum Product Diversity," American Economic Review, June 1977, 67, 297-308.

Dupor, Bill, "Aggregation and irrelevance in multi-sector models," Journal of Monetary Economics, April 1999, 43 (2), 391-409.

Erosa, Andres, Tatyana Koreshkova, and Diego Restuccia, "On the Aggregate and Distributional Implications of Productivity Differences Across Countries," 2006. University of Toronto working paper.

Gabaix, Xavier, "The Granular Origins of Aggregate Fluctuations," 2005. MIT working paper.

Gollin, Douglas, "Getting Income Shares Right," Journal of Political Economy, April 2002, $110(2), 458-474$.

Grossman, Gene M. and Giovanni Maggi, "Diversity and Trade," American Economic Review, December 2000, 90 (5), 1255-1275.

Hall, Robert E. and Charles I. Jones, "Why Do Some Countries Produce So Much More Output per Worker than Others?," Quarterly Journal of Economics, February 1999, 114 (1), 83-116.

Hausmann, Ricardo, Dani Rodrik, and Andres Velasco, "Growth Diagnostics," March 2005. Kennedy School of Government working paper.

Hirschman, Albert O., The Strategy of Economic Development, New Haven, CT: Yale University Press, 1958. 
Horvath, Michael T.K., "Cyclicality and Sectoral Linkages: Aggregate Fluctuations from Independent Sectoral Shocks," Review of Economic Dynamics, October 1998, 1 (4), 781-808.

Howitt, Peter, "Endogenous Growth and Cross-Country Income Differences," American Economic Review, September 2000, 90 (4), 829-846.

Hsieh, Chang-Tai and Peter J. Klenow, "Misallocation and Manufacturing TFP in China and India," July 2007. University of California at Berkeley working paper.

Hulten, Charles R., "Growth Accounting with Intermediate Inputs," Review of Economic Studies, 1978, 45 (3), 511-518.

Jones, Charles I., “The Input-Output Multiplier and Economic Development," 2007. U.C. Berkeley, work in progress.

__ , "A Simple Mincerian Approach to Endogenizing Schooling,” April 2007. U.C. Berkeley working paper.

Jorgenson, Dale W., Frank M. Gollop, and Barbara M. Fraumeni, Productivity and U.S. Economic Growth, Cambridge, MA: Harvard University Press, 1987.

Judd, Kenneth L., "Redistributive taxation in a simple perfect foresight model," Journal of Public Economics, October 1985, 28 (1), 59-83.

Klenow, Peter J. and Andres Rodriguez-Clare, "The Neoclassical Revival in Growth Economics: Has It Gone Too Far?," in Ben S. Bernanke and Julio J. Rotemberg, eds., NBER Macroeconomics Annual 1997, Cambridge, MA: MIT Press, 1997.

_ and _ _ "Extenalities and Growth," in Philippe Aghion and Steven Durlauf, eds., Handbook of Economic Growth, Amsterdam: Elsevier, 2005.

Kremer, Michael, “The O-Ring Theory of Economic Development," Quarterly Journal of Economics, August 1993, 108 (4), 551-576.

Lagos, Ricardo, “A Model of TFP,” Review of Economic Studies, 2006, 73 (4), 983-1007.

Leontief, Wassily, "Quantitative Input and Output Relations in the Economic System of the United States," Review of Economics and Statistics, 1936, 18 (3), 105-125.

Long, John B. and Charles I. Plosser, "Real Business Cycles," Journal of Political Economy, February 1983, 91 (1), 39-69.

Mankiw, N. Gregory, David Romer, and David Weil, "A Contribution to the Empirics of Economic Growth," Quarterly Journal of Economics, May 1992, 107 (2), 407-438.

Manuelli, Rodolfo and Ananth Seshadri, "Human Capital and the Wealth of Nations," March 2005. University of Wisconsin working paper.

Marimon, Ramon and Vincenzo Quadrini, "Competition, Innovation and Growth with Limited Commitment,” 2006. U.S.C. working paper.

Milgrom, Paul and John Roberts, "The Economics of Modern Manufacturing: Technology, Strategy, and Organization," American Economic Review, June 1990, 80 (3), 511-528. 
Murphy, Kevin M., Andrei Shleifer, and Robert W. Vishny, "Industrialization and the Big Push," Journal of Political Economy, October 1989, 97 (5), 1003-26.

Nunn, Nathan, "Relationship Specificity, Incomplete Contracts, and the Pattern of Trade," Quarterly Journal of Economics, forthcoming 2007.

Parente, Stephen L. and Edward C. Prescott, "Monopoly Rights: A Barrier to Riches," American Economic Review, December 1999, 89 (5), 1216-1233.

_ , Richard Rogerson, and Randall Wright, "Homework in Development Economics: Household Production and the Wealth of Nations," Journal of Political Economy, August 2000, 108 (4), 680-687.

Prescott, Edward C., "Needed: A Theory of Total Factor Productivity," International Economic Review, August 1998, 39 (3), 525-51.

Restuccia, Diego and Richard Rogerson, "Policy Distortions and Aggregate Productivity with Heterogeneous Plants," April 2007. NBER Working Paper 13018.

_ _ Dennis Tao Yang, and Xiaodong Zhu, "Agriculture and Aggregate Productivity: A Quantitative Cross-Country Analysis," March 2006. University of Toronto working paper.

Rodriguez-Clare, Andres, "Multinationals, Linkages, and Economic Development," American Economic Review, September 1996, 86 (4), 852-73.

Rodrik, Dani, "Coordination Failures and Government Policy: A Model with Applications to East Asia and Eastern Europe," Journal of International Economics, February 1996, 40 (1-2), 1-22.

Romer, Paul M., "New Goods, Old Theory, and the Welfare Costs of Trade Restrictions," Journal of Development Economics, 1994, 43, 5-38.

Rosen, Sherwin, "The Economics of Superstars," American Economic Review, December 1981, 71 (5), 845-58.

Waugh, Michael E., "International Trade and Income Differences," November 2007. University of Iowa working paper.

Yamano, Norihiko and Nadmim Ahmad, "The OECD Input-Output Database, 2006 Edition,” October 2006. OECD STI Working Paper 2006/8.

Yi, Kei-Mu, "Can Vertical Specialization Explain the Growth of World Trade?, Journal of Political Economy, February 2003, 111 (1), 52-102. 